\title{
Central Retinal Arterial and Venous Occlusion in a Patient with Systemic Sclerosis and a Review of the Related Literature
}

\author{
Aya Mori ${ }^{1}$, Kimimasa Nakabayashi ${ }^{1,4}{ }^{\text {, }}$, Hiroko Konishi ${ }^{2}$, Ippei Doi $^{3}$, Rie Tagaya $^{1}$, Aya Nakase $^{1}$, \\ Masayoshi Iwakami ${ }^{1}$ \\ ${ }^{1}$ Department of Internal Medicine, Kugayama Hospital, Tokyo, Japan \\ ${ }^{2}$ Department of Ophthalmology, Kugayama Hospital, Tokyo, Japan \\ ${ }^{3}$ Department of Radiology, Kugayama Hospital, Tokyo, Japan \\ ${ }^{4}$ Department of Internal Medicine, Kyorin University School of Medicine, Tokyo, Japan
}

Email address:

iris_aya0111@hotmail.co.jp (A. Mori),kiminaka@krd.biglobe.ne.jp (K. Nakabayashi), hiroko.mappy0623@icloud.com (H. Konishi), i-doi@kugayama.or.jp (I. Doi), r-tagaya@kugayama.or.jp (R. Tagaya), a-nakase@kugayama.or.jp (A. Nakase), m-iwakami@kugayama.or.jp (M. Iwakami)

${ }^{*}$ Corresponding author

\section{To cite this article:}

Aya Mori, Kimimasa Nakabayashi, Hiroko Konishi, Ippei Doi, Rie Tagaya, Aya Nakase, Masayoshi Iwakami. Central Retinal Arterial and Venous Occlusion in a Patient with Systemic Sclerosis and a Review of the Related Literature. American Journal of Internal Medicine.

Vol. 9, No. 4, 2021, pp. 214-218. doi: 10.11648/j.ajim.20210904.19

Received: July 14, 2021; Accepted: August 5, 2021; Published: August 27, 2021

\begin{abstract}
Systemic sclerosis (SSc) is known to cause serious complications at an advanced stage. However, serious ocular complications such as central retinal artery occlusion (CRAO) and/or central retinal vein occlusion (CRVO) have only been reported in a few cases to date. A 51-year-old man with severe Raynaud's phenomenon, scleroderma up to the forearm and a negative anti-nuclear antibody (ANA) finding developed pulmonary fibrosis (PF) and was admitted to the hospital for the treatment of dyspnea under the diagnosis of SSc. A transbronchial lung biopsy performed 10 days after admission demonstrated mucoid intimal thickening (MIT) of the small arteries in the peripheral lung tissue and the bronchial wall. Prednisolone (PSL), ciclosporin and nintedanib were prescribed for PF treatment but failed to induce any apparent improvement in dyspnea. Finally, methylprednisolone pulse therapy ( $1.0 \mathrm{~g}, 3$ times) and intravenous cyclophosphamide (IVCY, $500 \mathrm{mg}, 6$ times) therapy were instituted with a subsequent decrease in the patient's Krebs von den Lungen 6 (KL-6) and surfactant protein D (SP-D) levels. During IVCY therapy, the patient experienced blurred vision in the right eye, and this was diagnosed as being due to CRAO and CRVO. However, the patient did not manifest any embolic, coagulopathic, or vasculitic symptoms, and there were no abnormal laboratory data suggesting these diseases in relation to this symptom. Therefore, the ocular occlusion was presumed to be due to MIT of small arteries, in addition to severe Raynaud's phenomenon. Thus, we report the findings of this important case, despite the fact that it lacks a retinal pathology.
\end{abstract}

Keywords: Systemic Sclerosis, Central Retinal Artery Occlusion, Raynaud's Phenomenon, Pulmonary Fibrosis, Mucoid Intimal Thickening

\section{Introduction}

SSc is known to result in serious complications at an advanced stage [1,2]. However, only a small number of cases in which serious ocular complications such as CRAO and/or CRVO developed have been reported in major journals to date
[3-11], and few reports have described retinal pathological findings associated with SSc $[3,4,6]$. We encountered a case of CRAO with CRVO in a patient with SSc who had MIT of the arteries in the peripheral lung tissue and the bronchial wall. 
Herein, we describe the findings in detail, discuss the etiopathogenesis of CRAO/CRVO, and compare our case with previous cases.

\section{Case Presentation}

Table 1. Main laboratory data at admission.

\begin{tabular}{|c|c|}
\hline Urine & Coagulation \\
\hline Protein (-) & PT $12.0 \mathrm{sec}$ \\
\hline Glucose (-) & PT-INR 1.19 \\
\hline Sediments: WNL & APTT $58.1 \mathrm{sec}$ \\
\hline Hematology & Serum immunology \\
\hline $\mathrm{Hb} 13.0 \mathrm{~g} / \mathrm{dl}$ & CRP $0.78 \mathrm{mg} / \mathrm{dl}$ \\
\hline Ht $40.1 \%$ & KL-6 $721 \mathrm{U} / \mathrm{ml}$ \\
\hline RBCs $474 \times 10^{4} / \mu 1$ & SP-D $305.3 \mathrm{ng} / \mathrm{ml}$ \\
\hline WBCs $6,520 / \mu 1$ & ANA $<40 \times$ \\
\hline Neutrophils $65.7 \%$ & Anti-Scl $70 \mathrm{Ab} 0.9 \mathrm{U} / \mathrm{ml}$ \\
\hline Lymphocytes $21.2 \%$ & Anti-centromere $\mathrm{Ab}<0.5 \mathrm{U} / \mathrm{ml}$ \\
\hline Monocytes $8.7 \%$ & Wasserman R negative \\
\hline PLTs $42 \times 10^{4} / \mu 1$ & Arterial blood gas \\
\hline Blood chemistry & pH 7.461 \\
\hline $\mathrm{TP} 8.0 \mathrm{~g} / \mathrm{dl}$ & $\mathrm{PaO}_{2} 71.2 \mathrm{mmHg}$ \\
\hline Alb $3.3 \mathrm{~g} / \mathrm{dl}$ & $\mathrm{PaCO}_{2} 39.1 \mathrm{mmHg}$ \\
\hline AST $38 \mathrm{U} / 1$ & $\mathrm{HCO}_{3}^{-} 27.3 \mathrm{mmol} / \mathrm{L}$ \\
\hline ALT 27 U/1 & BE $3.4 \mathrm{mmol} / \mathrm{L}$ \\
\hline LDH 262 U/1 & Respiratory function \\
\hline ALP 205 U/1 & FVC $1.5 \mathrm{~L}$ \\
\hline TC $188 \mathrm{mg} / \mathrm{dl}$ & $\% \mathrm{FVC} 42.6 \%$ \\
\hline TG 73 mg/dl & $\mathrm{FEV}_{1.0} 1.37 \mathrm{~L}$ \\
\hline LDL 146 mg/dl & $\% \mathrm{FEV}_{1} 46.3 \%$ \\
\hline BUN $12.9 \mathrm{mg} / \mathrm{dl}$ & FEV1\% $41.3 \%$ \\
\hline $\mathrm{Cr} 0.70 \mathrm{mg} / \mathrm{dl}$ & $\%$ DLCO $55.6 \%$ \\
\hline $\mathrm{BS} 110 \mathrm{mg} / \mathrm{dl}$ & \\
\hline $\mathrm{HbA}_{1} \mathrm{c}(\mathrm{NGSP}) 6.2 \%$ & \\
\hline
\end{tabular}

A 51-year-old man had experienced the manifestations of Raynaud's phenomenon, as well as skin tightness on the fingers and forearms, for a period of 3 years but had no history of treatment for hypertension. The patient was admitted to the hospital with dyspnea in March 201X. A physical examination showed a blood pressure (BP) of $158 / 98 \mathrm{~mm} \mathrm{Hg}$, a pulse of $117 /$ min with no arrythmia, a body temperature of $36.1{ }^{\circ} \mathrm{C}$, peripheral oxygen saturation $\left(\mathrm{SpO}_{2}\right)$ of $97 \%$, bilateral fine crackles and no cardiac murmur. Scleroderma was observed, and the Rodnan skin score was 14 (edematous). The laboratory data are presented in Table 1 . The main abnormal findings were as follows: ANA, negative according to an immunofluorescence study; anti-Scl-70 and anti-centromere antibodies, negative; and KL-6 and SP-D, elevated. Arterial blood gas analysis showed a $\mathrm{pH}$ of 7.461, a partial pressure of oxygen $\left(\mathrm{PaO}_{2}\right)$ of 71.2 and a partial pressure of carbon dioxide $\left(\mathrm{PaCO}_{2}\right)$ of $39.1 \mathrm{~mm} \mathrm{Hg}$. A respiratory function test showed a forced vital capacity (FVC) of $1.5 \mathrm{~L}$, a $\% \mathrm{FVC}$ of $42.6 \%$ and a $\%$ diffusion capacity of carbon monoxide (\% DLCO) of $55.6 \%$. Chest X-ray and computed tomography (CT) revealed nonspecific interstitial pneumonitis (NSIP) (peripheral interstitial fibrosis without honeycomb lesions) [12]. The diagnosis at admission according to the Classification Criteria for Systemic Sclerosis: An ACR-EULAR Collaborative Initiative [13], was SSc with negative ANA and NSIP findings. A transbronchial lung biopsy was performed on the 10th day after admission. The sampled peripheral lung tissue and bronchial wall showed narrowing of the internal space of the small arteries and one venule with a mucoid substance. The observed narrowing of the arteries was associated with increased elastosis of the internal elastic fibers (elastica-van Gieson [EVG] staining) (Figure 1). However, no fibrinoid necrosis or granulomatous lesions, including giant cells and inflammatory vasculitic lesions, were found in the arterial wall or in any other tissues in the obtained specimens. The amount of alveolar tissue obtained from the specimens was very small and thus insufficient to confirm a diagnosis of PF. The pathological diagnosis was MIT of the small arteries [14] without fibrinoid degeneration or inflammatory vasculitic lesions. A nailfold capillaroscopic study was not performed during the patient's hospital stay.

We started the patient on NSIP treatment with oral PSL at $40 \mathrm{mg}$ /day (Figure 2). However, his serum KL-6 and SP-D levels increased. Therefore, ciclosporin at $150 \mathrm{mg} /$ day and nintedanib at $200 \mathrm{mg}$ /day were added for NSIP treatment but without any apparent improvement. Finally, methylprednisolone pulse therapy (1.0 g, 3 times) and monthly IVCY therapy (500 mg, 6 times) were instituted, resulting in an eventual decrease in his KL-6 and SP-D levels. During these treatments, the patient's BP remained high at approximately $150 / 90-80 \mathrm{~mm} \mathrm{Hg}$, but the patient did not manifest malignant hypertension or symptoms or laboratory data suggestive of scleroderma renal crisis (SRC) [15]. However, the patient developed blurred vision in the right eye; his visual acuity was 0.03 . Optical examination of the right fundus revealed whitish cloudiness in the arcade area, cotton-wool patches, hemorrhagic spots, tortuous arteries and veins, peripheral hemorrhaging and papilledema (Figure 3). Optical examination of the left fundus showed hypertension grade 1 and sclerosis grade $1\left(\mathrm{H}_{1} \mathrm{~S}_{1}\right)$ without any exudation or hemorrhaging. These findings resulted in a diagnosis of CRAO and CRVO [16, 17]. At this point, the patient's laboratory data were largely within the normal range; they were as follows: C-reactive protein (CRP), $0.23 \mathrm{mg} / \mathrm{dl}$; serum creatinine, $0.57 \mathrm{mg} / \mathrm{dl}$; hemoglobin, $14.3 \mathrm{~g} / \mathrm{dl}$; white blood cells, $9,600 / \mu 1$; platelets, $30 \times 10^{4} / \mu \mathrm{l}$; total protein (TP), $6.4 \mathrm{~g} / \mathrm{dl}$; aspartate transaminase/alanine aminotransferase (AST/ALT), 29/40 U/1; alkaline phosphatase (ALP), $274 \mathrm{U} / 1$; lactate dehydrogenase (LDH), $250 \mathrm{U} /$; p proteinuria (-); glycosuria (-); and urobilinogen $( \pm)$. No bleeding or coagulation tendencies were found clinically in relation to this event, and the patient's a2-plasmin inhibitor-plasmin complex (PIC) and thrombin-antithrombin complex (TAT) levels were almost normal (Figure 2). In addition, the levels of myeloperoxidase anti-neutrophil cytoplasmic antibody (MPO-ANCA, 0.6 $\mathrm{IU} / \mathrm{ml},<3.4)$, proteinase $3\left(\mathrm{PR}_{3}\right)$-ANCA $(1.0 \mathrm{IU} / \mathrm{ml},<1.9)$, activated partial thromboplastin time (APTT, $34.2 \mathrm{sec}$, 26.0 38.0), anticardiolipin IgG (4 U/ml, <10) and lupus anticoagulant (0.2, dilute Russell viper venom time [dRVVT], $<1.2$ ) were confirmed. Furthermore, no apparent stenosis or plaques in either carotid artery were observed on echo examination, nor were any apparent abnormalities of the cardiac walls or thoracic aorta noted on CT. We observed 
manifestations of severe Raynaud's phenomenon in all of the patient's fingers, including the thumbs, and up to the forearms, even in the hospital. Therefore, we did not administer specific anticoagulant therapy but instead advised the patient to keep his body warm. The patient did not show any further eye-related complications, and the visual acuity of the right eye recovered to 0.1 .

\section{Discussion}

SSc patients are generally reported to be ANA positive, but approximately $10 \%$ of patients are documented as ANA negative $[1,2]$. Serious complications of SSc are known to include renal crisis, severe PF, pulmonary hypertension and gastrointestinal dysfunction $[1,2]$. These complications are frequently associated with fibrinoid degeneration of the small arteries and arterioles, resulting in renal crisis and other related issues $[18,19]$. However, some reports have described MIT of small renal arteries and progression to renal crisis [20,21]. We found nine articles in major journals that described ocular findings with acute visual impairment in SSc [3-11] (Table 2). Nine cases were reported to be due to CRAO, whereas five were due to CRVO. However, references to retinal vascular pathology were found in only four cases with diagnoses of CRAO. Two of these four CRAO cases showed fibrinoid degeneration of the retinal arteries due to malignant hypertension with SRC [3], whereas the remaining two cases of CRAO showed a different pathology. The retinal arteries in one case were almost obliterated by amorphous materials [4] and the other case was obliterated by fibroproliferative materials [6]. These two cases were not associated with fibrinoid degeneration of the arterial walls. The former case was diagnosed as MIT vasculopathy, and the latter case was considered an eventually progressed case from MIT [14]. Regarding CRVO, there have been no case reports of retinal vascular pathology. One case described by Littlejohn et al. [5], in which the patient lacked malignant hypertension and any pathology including the retina, was hypothesized by the authors to have been associated with CRAO. They considered this finding to be associated with MIT lesions because the patient showed neither malignant hypertension nor SRC. In another two cases of CRVO reported by Rodonto et al. [7] without retinal or other pathologies, the patients displayed normotensive status and CRVO occurrence in the early phase of SSc, but there were no explanatory data concerning etiopathogenesis. The remaining two CRVO cases were presumed to have been caused by pathological processes associated with endothelial cells in SSc, but there was no direct evidence of this pathology $[8,11]$. CRAO and/or CRVO are not frequent complications of SSc, but they are serious manifestations. Therefore, reports of similar cases, including their pathologies, should be followed.

Table 2. Central retinal artery and/or vein occlusion in patients with scleroderma-reported cases.

\begin{tabular}{llll}
\hline Authors & Publication year & Journal & Retinal findings (number of cases) \\
\hline Ashton N et al. & 1968 & J Path Bact & CRAO $(\mathrm{n}=2)^{*}$ \\
Farkas TG et al. & 1972 & Am J Opathol & CRAO $(\mathrm{n}=1)^{*}$ \\
Littlejohn GO et al. & 1981 & Ann Rheum Dis & CRVO $(\mathrm{n}=1)$ \\
Saari K et al. & 1981 & Opthalmo & CRVO $(\mathrm{n}=1)$ \\
Konuk O et al. & 2006 & Retina & CRAO $(\mathrm{n}=1)$ \\
Raja MS et al. & 2009 & Cases J & CRAO $(\mathrm{n}=1)$ \\
Basquets J et al. & 2013 & Semi Arthritis Rheum & CRAO $(\mathrm{n}=3)^{* *}$ \\
Rotondo C et al. & 2014 & J Rheumatol & CRVO $(\mathrm{n}=2)$ \\
Malik F et al. & 2015 & CRAO $(\mathrm{n}=1)$ & 8 \\
\hline
\end{tabular}

CRAO: central retinal artery occlusion; CRVO: central retinal vein occlusion

*: retinal pathology examined, $* *$ : one case with retinal pathology examined

Considered together, these reports suggest that CRAO in SSc might be caused by two different pathogeneses-fibrinoid degeneration or MIT of the arterial walls - when vasculitic diseases (such as giant cell arteritis and MPO- and $\mathrm{PR}_{3}$-ANCA-associated vasculitis), embolic diseases and coagulopathic diseases are excluded [9, 22, 23]. In the present case, embolic diseases were deemed unlikely based on carotid artery echo and chest CT findings. In addition, no coagulopathic data were observed, and the patient did not show any vasculitic symptoms, including fever, weight loss, arthralgia, skin rashes, peripheral numbness, or ANCA positivity. Therefore, the MIT of the vessels is attributed to the pathogenesis of CRAO and CRVO in this case. MIT is caused by the secretion of various components (mainly acidic mucopolysaccharides) by the altered endothelium and the basal lamina of the microvasculature. These components are known to accumulate beneath the vascular endothelium [24]. This pathogenesis is thought to be caused by the presence of anti-endothelial cell antibodies and other serum factors [24-27]. In addition, MIT has been occasionally reported to induce serious complications in scleroderma [18-21]. In contrast, the precise pathogenesis of CRVO in SSc remains unclear.

\section{Conclusion}

We reported one very interesting case of CRAO and CRVO. Our patient did not have ocular pathology but showed MIT of arteries and veins in the peripheral lung tissue and bronchial wall. This tissue was obtained through a lung biopsy that was performed at an early stage of the patient's hospitalization. No fibrinoid degeneration or vasculitic lesions were found in the 
biopsy specimens. The disease course during hospitalization did not include any clinical manifestations of malignant hypertension or any laboratory data indicating SRC, vasculitis or coagulopathy. Based on these data, we strongly suspect that the CRAO and CRVO were due to MIT of the artery in the lamina cribrosa of the eye in addition to severe Raynaud's phenomenon. The artery and vein in the lamina cribrosa share the same adventitia, and arterial events also influence the vein. NSIP continued to be relatively severe and necessitated nasal oxygen therapy.
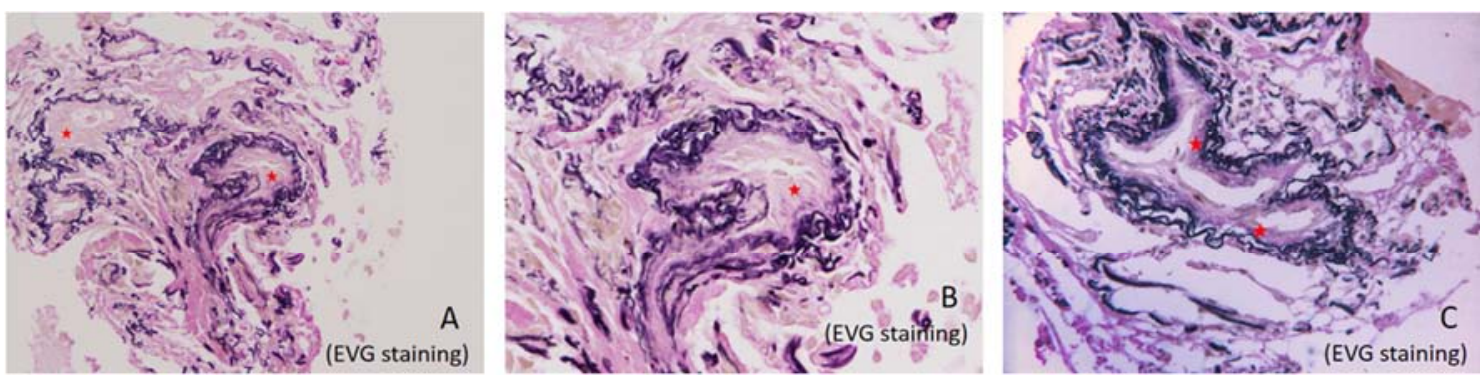

Figure 1. Pathological findings of vessels in the peripheral lung and the bronchus obtained by transbronchial lung biopsy. A: One area of the peripheral lung tissue showing marked internal space narrowing of one arteriole and one venule with a mucoid substance. $\star$ indicates mucoid substance (EVG staining, $\times 200)$. $B$ : The same arteriole at a higher magnification (EVG staining, $\times 400)$. C: One small artery in the bronchial wall showing a lower degree of MIT (EVG staining, $\times 400$ ).

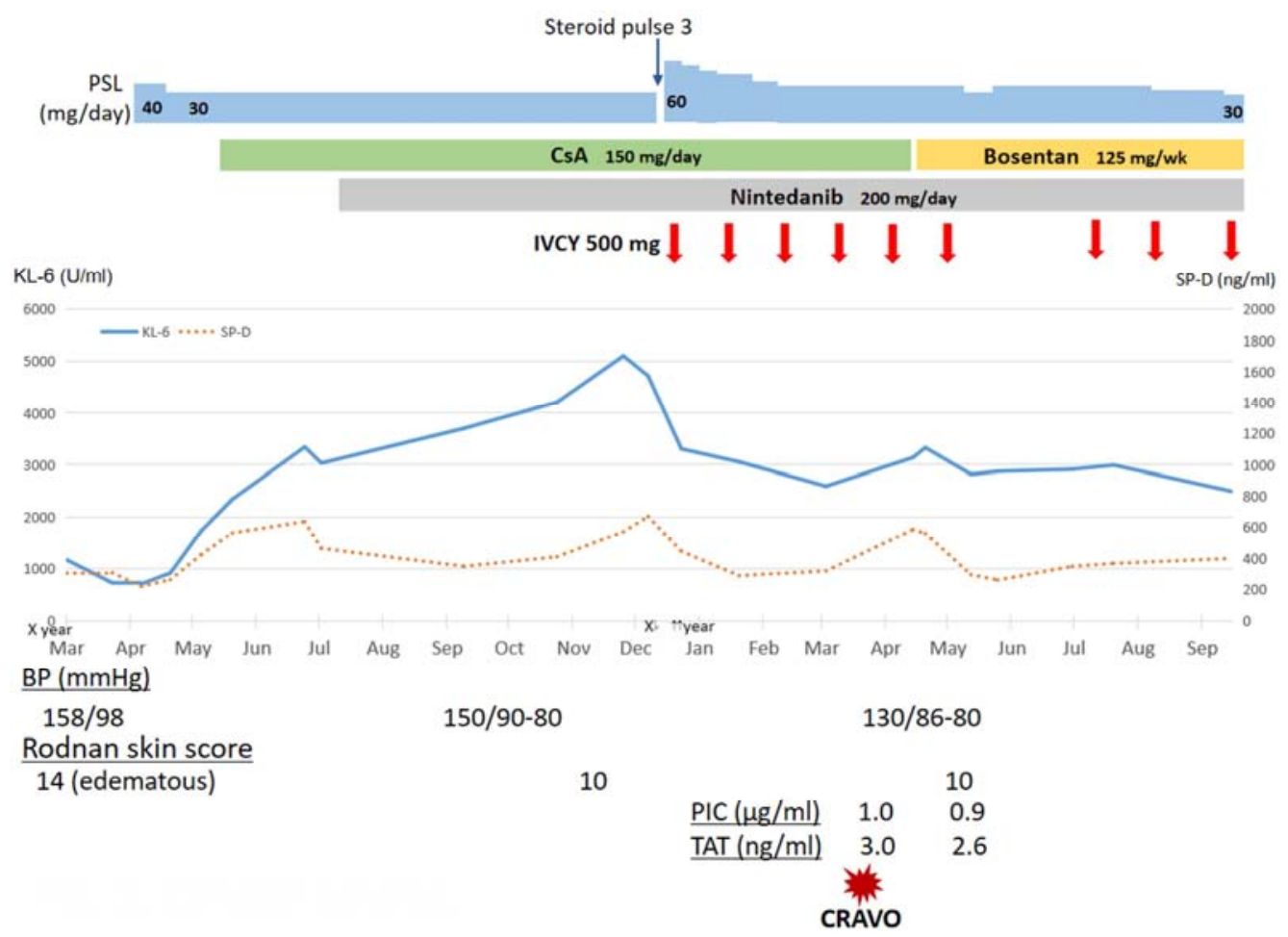

Figure 2. Clinical course.
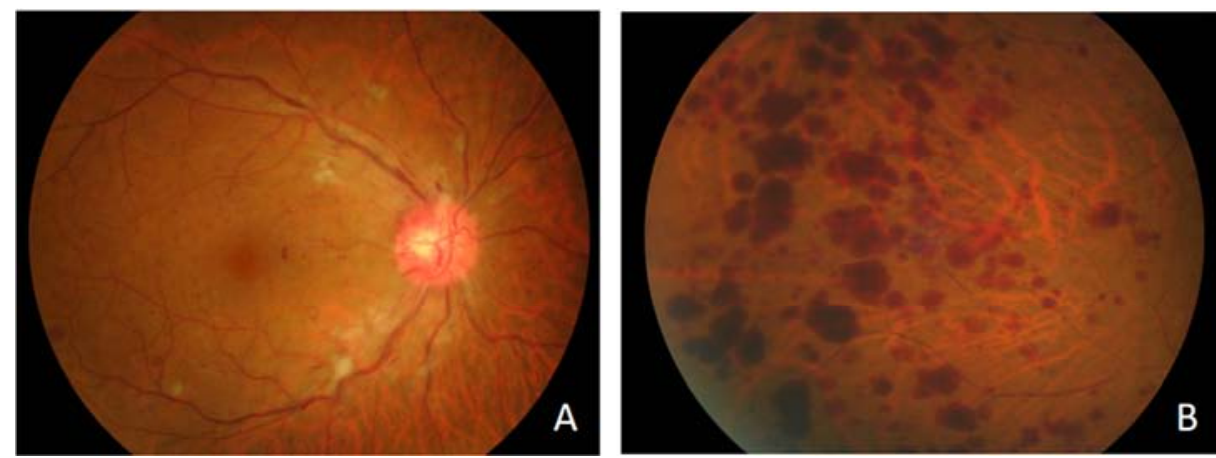

Figure 3. Optic findings of the right fundus (seven days after the onset of visual disturbance). Optic image of the fundus of the right eye showing whitish cloudiness in the arcade area, cotton-wool patches, hemorrhagic spots, papilledema, tortuous arteries and veins, and peripheral hemorrhaging (A, B). These findings led to the diagnosis of CRAO and CRVO. 


\section{References}

[1] Kuwana M, Kaburaki J, Okano Y et al. Clinical and prognostic associations based on serum antinuclear antibodies in Japanese patients with systemic sclerosis. Arthritis Rheum. 1994; 37: $75-83$.

[2] Hesselstrand R, Scheja A, Shen GQ et al. The association of antinuclear antibodies with organ involvement and survival in systemic sclerosis. Rheumatology. 2003; 42: 534-40.

[3] Ashton N, Coomes EN, Garner A et al. Retinopathy due to progressive systemic sclerosis. J Pathol Bacteriol. 1968; 96: 259-68.

[4] Farkas TG, Sylvester V, Archer D. The choroidopathy of progressive systemic sclerosis (scleroderma). Am J Ophthalmol. 1972; 74: 875-86.

[5] Littlejohn GO, Urowitz MB, Pavlin CJ. Central retinal vein occlusion and scleroderma: implications for sclerodermatous vascular disease. Ann Rheum Dis. 1981; 40: 96-9.

[6] Busquets J, Lee Y, Santamarina L et al. Acute retinal artery occlusion in systemic sclerosis: a rare manifestation of systemic sclerosis fibroproliferative vasculopathy. Semin Arthritis Rheum. 2013; 43: 204-8.

[7] Rotondo C, Lopalco G, Lapadula G et al. Retinal vessels thrombosis as onset manifestation of systemic sclerosis: 3 clinical cases. J Rheumatol. 2014; 41: 2495-6.

[8] Saari K, Rudenberg H, Laitinen O. Bilateral central retinal vein occlusion in a patient with scleroderma. Ophthalmologica. 1981; 182: 7-12.

[9] Konuk O, Ozdek S, Onal B et al. Ocular ischemic syndrome presenting as central retinal artery occlusion in scleroderma. Retina. 2006; 26: 102-4.

[10] Raja MS, Marshall T, Burton BJ. Acute central retinal artery occlusion presenting as CREST syndrome: a case report. Cases J. 2009; 2: 9-12.

[11] Malik F, Habash AA. Presentation of acute central retinal vein occlusion in scleroderma. Saudi J Ophthalmol. 2015; 29: 156-9.

[12] Desai SR, Veeraraghavan S, Hansell DM et al. CT features of lung disease in patients with systemic sclerosis: Comparison with idiopathic pulmonary fibrosis and nonspecific interstitial pneumonia. Radiology. 2004; 232: 560-7.

[13] van den Hoogen F, Khanna D, Fransen J et al. 2013 Classification criteria for systemic sclerosis: An ACR-EULAR collaborative initiative. Arthritis Rheum. 2013; 65: 2737-47.
[14] Laszik ZG, Silva FG. Systemic sclerosis (systemic scleroderma). In: Jennette JC, Olson JL, Schwartz MM, Silva FG, editors. Heptinstall's Pathology of the Kidney, Sixth edition. Philadelphia: Lippincott Williams \& Wilkins; 2006: P. 730-40.

[15] Butler EA, Baron M, Fogo AB et al. Generation of a Core Set of Items to Develop Classification Criteria for Scleroderma Renal Crisis Using Consensus Methodology. Arthritis Rheumatol. 2019; 71: 964-71.

[16] Hayreh SS, Zimmerman MB. Central retinal artery occlusion: visual outcome. Am J Ophthalmol. 2005; 140: 376-91.

[17] Jorizzo PA, Klein ML, Shults WT et al. Visual recovery in combined central retinal artery and central retinal vein occlusion. Am J Ophthalmol. 1987; 104: 358-63.

[18] Batal I, Domsic RT, Medsger TA et al. Scleroderma renal crisis: A pathology perspective. Int J Rheumatol. 2010; 2010: 543704.

[19] Trostle DC, Bedetti CD, Steen VD et al. Renal vascular histology and morphometry in systemic sclerosis. A case-control autopsy study. Arthritis Rheum. 1988; 31: 393-400.

[20] Ubukata M, Mitsuhashi A, Nishizawa $Y$ et al. Anticentromere antibody-positive scleroderma renal crisis requiring dialysis. Intern Med. 2018; 57: 3479-83.

[21] Jacquier M, Mousson C, Rebibou J et al. Scleroderma renal crisis in a systemic sclerosis with anti-PM/Scl antibodies. Kidney Int Reports. 2019; 4: 1499-502.

[22] Carrero JL, Novoa Sanjurjo FJ. Bilateral cilioretinal artery occlusion in antiphospholipid syndrome. Retina. 2006; 26: 104-6.

[23] Chu ER, Chen CS. Concurrent central retinal artery occlusion and branch retinal vein occlusion in giant cell arteritis. Clin Ophthalmol. 2010; 4: 565-7.

[24] Frech TM, Revelo MP, Drakos SG et al. Vascular leak is a central feature in the pathogenesis of systemic sclerosis. J Rheumatol. 2012; 39: 1385-91.

[25] Müller-Ladner U, Distler O, Ibba-Manneschi L et al. Mechanisms of vascular damage in systemic sclerosis. Autoimmunity. 2009; 42: 587-95.

[26] Salojin KV, Le Tonquèze M, Saraux A, et al. Antiendothelial cell antibodies: useful markers of systemic sclerosis. Am J Med. 1997; 102: 178-85.

[27] Kahaleh MB, Fan PS. Mechanism of serum-mediated endothelial injury in scleroderma: identification of a granular enzyme in scleroderma skin and sera. Clin Immunol Immunopathol. 1997; 83: 32-40. 